Electrical Circuit Analysis and Design 


\section{Other Macmillan titles of related interest}

W. A. Atherton, From Compass to Computer

B. R. Bannister and D. G. Whitehead, Fundamentals of Modern Digital Systems

J. C. Cluley, Transducers for Microprocessor Systems

R. F. W. Coates, Modern Communication Systems, second edition

Donard de Cogan, Solid State Devices - A Quantum Physics Approach

C. W. Davidson, Transmission Lines for Communication, second edition

M. E. Goodge, Analog Electronics

M. E. Goodge, Semiconductor Device Technology

B. A. Gregory, An Introduction to Electrical Instrumentation and

Measurement Systems, second edition

Paul A. Lynn, An Introduction to the Analysis and Processing of Signals, third edition

Paul A. Lynn, Electronic Signals and Systems

J. E. Parton, S. J. T. Owen and M. S. Raven, Applied Electromagnetics, second edition

P. Silvester, Electric Circuits

Trevor J. Terrell, Introduction to Digital Filters, second edition

M. J. Usher, Sensors and Transducers

L. A. Warnes, Electronic Materials

B. W. Williams, Power Electronics - Devices, Drivers, Applications and

Passive Components

G. Williams, An Introduction to Electrical Circuit Theory

\section{Macmillan New Electronics Series}

Series Editor: Paul A. Lynn

Rodney F. W. Coates, Underwater Acoustic Systems

W. Forsythe and R. M. Goodall, Digital Control

Paul A. Lynn, Digital Signals, Processors and Noise

Paul A. Lynn, Radar Systems

A. F. Murray and H. M. Reekie, Integrated Circuit Design

F. J. Owens, Signal Processing of Speech

Dennis N. Pim, Television and Teletext

M. J. N. Sibley, Optical Communications

Martin S. Smith, Introduction to Antennas

P. M. Taylor, Robotic Control

G. S. Virk, Digital Computer Control Systems

Alan Waters, Active Filter Design 


\title{
Electrical Circuit Analysis and Design
}

\author{
Noel M. Morris \\ formerly Principal Lecturer \\ Staffordshire University
}

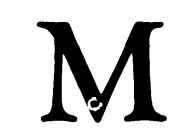

MACMILLAN 
All rights reserved. No reproduction, copy or transmission of this publication may be made without written permission.

No paragraph of this publication may be reproduced, copied or transmitted save with written permission or in accordance with the provisions of the Copyright, Designs and Patents Act 1988, or under the terms of any licence permitting limited copying issued by the Copyright Licensing Agency, 90 Tottenham Court Road, London W1P 9HE.

Any person who does any unauthorised act in relation to this publication may be liable to criminal prosecution and civil claims for damages.

First published 1993 by

THE MACMILLAN PRESS LTD

Houndmills, Basingstoke, Hampshire RG21 2XS

and London

Companies and representatives

throughout the world

ISBN 978-0-333-55483-8 ISBN 978-1-349-22560-6 (eBook)

DOI 10.1007/978-1-349-22560-6

A catalogue record for this book is available from the British Library 


\section{Contents}

Preface xii

Acknowledgements $\quad$ xv

1 Elements and Laws 1

1.1 Introduction 1

$\begin{array}{lll}1.2 & \text { Electric current } & 1\end{array}$

1.3 Voltage, e.m.f. and p.d. 3

$\begin{array}{lll}1.4 & \text { Power in d.c. circuits } & 4\end{array}$

1.5 Linear passive circuit elements 4

1.6 Resistance, conductance and Ohm's law 5

$\begin{array}{lll}1.7 & \text { Power in a resistive circuit } & 6\end{array}$

$\begin{array}{lll}1.8 & \text { Energy consumed in a resistive circuit } & 7\end{array}$

$\begin{array}{lll}1.9 & \text { Independent and dependent supply sources } & 8\end{array}$

1.9.1 The operational amplifier 9

$\begin{array}{ll}1.10 \text { Kirchhoff's laws } & 11\end{array}$

$\begin{array}{ll}1.11 \text { The double-suffix voltage notation } & 14\end{array}$

$\begin{array}{ll}1.12 \text { Practical (non-ideal) sources } & 16\end{array}$

$\begin{array}{ll}1.13 \text { Transformation of practical sources } & 17\end{array}$

$\begin{array}{ll}1.14 \text { Resistance of a series circuit } & 19\end{array}$

1.15 Voltage division in series-connected resistors 20

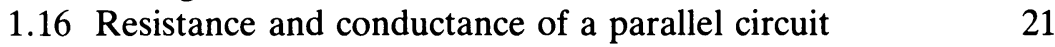

$\begin{array}{ll}1.17 \text { Current division in a parallel circuit } & 22\end{array}$

$\begin{array}{ll}\text { Unworked problems } & 24\end{array}$

2 Circuit Analysis $\quad 28$

$\begin{array}{lll}2.1 & \text { Introduction } & 28\end{array}$

$\begin{array}{ll}2.2 \text { Definitions and terminology } & 28\end{array}$

$\begin{array}{lll}2.3 & \text { Mesh analysis } & 31\end{array}$ 
2.4 General rules for writing mesh equations 34

$\begin{array}{lll}2.5 & \text { Solution of three simultaneous equations } & 34\end{array}$

2.6 Worked examples using mesh analysis 37

2.7 Nodal analysis $\quad 41$

2.8 General rules for writing nodal equations 44

2.9 Worked examples using nodal analysis 44

2.10 Network topology $\quad 49$

2.11 Loop analysis $\quad 52$

2.12 Duality $\quad 54$

$\begin{array}{ll}\text { Unworked problems } & 57\end{array}$

3 Circuit Theorems

$\begin{array}{lll}3.1 & \text { Introduction } & 61\end{array}$

$\begin{array}{lll}3.2 & \text { Linearity } & 61\end{array}$

$\begin{array}{lll}3.3 & \text { Principle of superposition } & 61\end{array}$

$\begin{array}{lll}3.4 & \text { Thévenin's theorem } & 63\end{array}$

$\begin{array}{lll}3.5 & \text { Norton's theorem } & 65\end{array}$

3.6 Relationship between Thévenin's and Norton's
circuits

$\begin{array}{lll}3.7 & \text { Reciprocity theorem } & 67\end{array}$

3.8 The maximum power transfer theorem 69

3.9 The parallel-generator (Millman's) theorem 70

3.10 Rosen's theorem or the general star-mesh 72

3.11 The star-delta, tee-wye or tee-pi transformation 73

3.12 The delta-star, wye-tee or pi-tee transformation 74

3.13 Summary of star-delta and delta-star transformations $\quad 74$

$\begin{array}{ll}\text { Unworked problems } & 75\end{array}$

4 Energy Storage Elements

$\begin{array}{lll}4.1 & \text { Introduction } & 79\end{array}$

$\begin{array}{lll}4.2 & \text { Capacitors } & 79\end{array}$

4.3 Energy stored in a capacitor $\quad 81$

4.4 Capacitors in parallel $\quad 82$

4.5 Capacitors in series $\quad 82$

4.6 Potential division in series-connected capacitors 83

$\begin{array}{lll}4.7 & \text { Inductance } & 83\end{array}$

4.8 Energy stored in an inductor $\quad 87$

\begin{tabular}{ll}
4.9 & Inductors in series \\
\hline
\end{tabular}

4.10 Inductors in parallel $\quad 88$

4.11 Duality between inductors and capacitors 90

4.12 Relationship between inductance, reluctance and the number of turns on a coil 
4.13 Mutual inductance

4.14 Direction of the mutually induced e.m.f. - the dot notation

4.15 Coefficient of coupling $\quad 93$

4.16 Mutually coupled coils in series and in parallel 94

Unworked problems

5 The Sinewave, Phasors and Power

5.1 Introduction

100

5.2 Mean or average value of an alternating quantity 100

5.3 The effective value or r.m.s. value of a periodic wave 102

$\begin{array}{lll}5.4 & \text { Phase angle } & 103\end{array}$

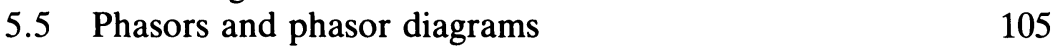

5.6 Representation of a sinusoidal quantity as a complex value

5.7 Impedance of elements 107

$\begin{array}{lll}\text { 5.7.1 Resistance } & 108\end{array}$

$\begin{array}{lll}\text { 5.7.2 Pure inductance } & 108\end{array}$

$\begin{array}{lll}5.7 .3 & \text { Pure capacitance } & 109\end{array}$

5.7.4 CIVIL - an a.c. mnemonic 110

5.8 The susceptance of elements 111

5.9 The admittance of elements 111

5.10 The impedance of elements in series 112

5.11 The admittance and impedance of elements in

5.12 Impedance and admittance of series-parallel circuits 115

$\begin{array}{ll}5.13 \text { Power and power factor } & 115\end{array}$

5.14 Power, VA and VAr absorbed by ideal elements . 117

$\begin{array}{ll}5.15 v-i \text { waveforms } & 118\end{array}$

5.16 Power consumed in an a.c. circuit $\quad 118$

$\begin{array}{ll}5.17 \text { Complex power } & 121\end{array}$

$\begin{array}{ll}\text { Unworked problems } & 122\end{array}$

6 Sinusoidal Steady-state Analysis $\quad 126$

$\begin{array}{lll}6.1 & \text { Introduction } & 126\end{array}$

6.2 Nodal, mesh and loop analysis 130

6.3 Principle of superposition 132

6.4 Thévenin's theorem and Norton's theorem 133

6.5 Millman's theorem 135

6.6 Rosen's, star-delta and delta-star theorems 136

$\begin{array}{ll}\text { 6.7 Maximum power transfer theorem } & 137\end{array}$

$\begin{array}{lll}6.8 & \text { a.c. circuits with dependent sources } & 138\end{array}$

$\begin{array}{ll}\text { Unworked problems } & 140\end{array}$ 
7 Polyphase Circuits

$\begin{array}{lll}7.1 & \text { Introduction } & 144\end{array}$

$\begin{array}{lll}7.2 & \text { Three-phase generation } & 144\end{array}$

7.3 Star-connection or Y-connection 145

$\begin{array}{lll}7.4 & \text { Phase sequence } & 146\end{array}$

7.5 Balanced and unbalanced systems 147

7.6 Phase and line voltages in a star-connected system 147

7.7 Delta-connected or mesh-connected three-phase source

7.8 Three-phase, four-wire, star-star system 150

7.8.1 Balanced supply, balanced load 151

7.8.2 Three-phase, four-wire, star-connected system with an unbalanced load

7.9 Three-phase, three-wire, star-star system 153

7.10 Delta-connected systems 155

7.10.1 Balanced delta-connected load with a balanced supply

7.10.2 Unbalanced delta-connected load with a balanced supply

7.10.3 Unbalanced delta-connected load with an unbalanced supply

7.11 Delta-connected supply and a star-connected load $\quad 159$

7.12 Star-connected supply and delta-connected load 159

7.13 Summary of balanced star- and delta-connected loads 160

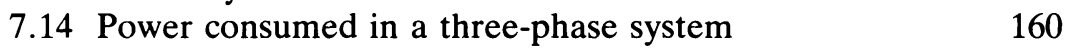

7.15 Power measurement in a three-phase system 162

7.16 The two-wattmeter method of power measurement 163

7.17 Introduction to symmetrical components 164

7.18 Analysis of unbalanced conditions 165

7.18.1 Power consumed by symmetrical components

Unworked problems

8 Two-port Networks 171

8.1 Introduction 171

8.2 Input impedance, output impedance, voltage gain, current gain and power gain

8.3 Admittance parameters or $y$-parameters 176

8.4 Impedance parameters or $z$-parameters $\quad 180$

8.5 Hybrid parameters or $h$-parameters 183

$\begin{array}{ll}\text { 8.6 Transmission parameters } & 186\end{array}$

8.7 Relationship between the $y$-, $z-, h$ - and $t$-parameters 189 
8.8 Interconnection between two-port networks 191

Unworked problems

9 The Transformer 198

$\begin{array}{lll}9.1 & \text { Introduction } & 198\end{array}$

9.2 The ideal transformer 198

9.3 Phasor diagram for an ideal transformer on no-load 201

9.4 Leakage flux in a transformer 203

9.5 Impedance matching with an ideal transformer 204

9.6 The ideal transformer as a two-port network 207

9.7 Thévenin's equivalent circuit of an ideal transformer $\begin{array}{ll}\text { and voltage regulation } & 208\end{array}$

9.8 The linear transformer 211

$9.9 T$ - and $\pi$-equivalent circuit of a linear transformer 214

$\begin{array}{ll}\text { Unworked problems } & 214\end{array}$

10 Transient Solution of Electrical Circuits 218

$\begin{array}{lll}10.1 & \text { Introduction } & 218\end{array}$

10.2 Classical solution of first-order systems 219

10.2.1 The time constant $\tau$ of a circuit 223

10.2.2 Circuits reducible to first-order format 223

$\begin{array}{lll}10.3 & \text { Classical solution of second-order systems } & 224\end{array}$

10.4 The Laplace transform 226

10.5 Step, impulse and ramp functions 227

10.6 Laplace transforms of some useful functions 233

10.7 Properties of the Laplace transform 237

10.8 Representation of circuit elements in the $s$ domain 242

10.9 Introduction to analysis of first-order systems using

10.10 Sinusoidal excitation of first-order systems 249

10.11 Solution of second-order circuits using Laplace

$10.12 s$-Domain transfer functions $\quad 258$

10.13 Transients in magnetically coupled circuits 259

$\begin{array}{ll}\text { Unworked problems } & 262\end{array}$

11 Complex Frequency, the s-Plane and Bode Diagrams 266

11.1 Introduction 266

11.2 The exponential form of a complex number 267

$\begin{array}{lll}11.3 & \text { Complex frequency } & 267\end{array}$

$\begin{array}{lll}11.4 & \text { The } s \text {-plane } & 268\end{array}$

11.5 Transformation of impedance into the $s$-domain 269 
11.6 Frequency response as a function of $\omega$

11.7 Transfer functions $\quad 276$

$\begin{array}{lll}11.8 & \text { Bode diagrams } & 280\end{array}$

11.9 Bode diagram of $\boldsymbol{H}(\mathrm{j} \omega)=K$

11.10 Bode diagram of $\boldsymbol{H}(\mathrm{j} \omega)=(\mathrm{j} \omega \tau)^{n} \quad 282$

11.11 Bode diagram of $\boldsymbol{H}(\mathrm{j} \omega)=(1+\mathrm{j} \omega \tau)$

11.12 Bode diagram of $\boldsymbol{H}(\mathrm{j} \omega)=(1+\mathrm{j} \omega \tau)^{n}$

10.13 Plot of $\boldsymbol{H}(j \omega)=1+2 \zeta\left[\frac{j \omega}{\omega_{0}}\right]+\left[\frac{j \omega}{\omega_{0}}\right]^{2}$

Unworked problems 296

12 Resonance 299

12.1 Introduction 299

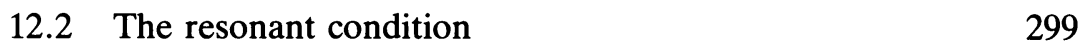

$\begin{array}{lll}12.3 & \text { Series resonance } & 300\end{array}$

12.3.1 Resonant frequency and frequency response $\quad 300$

12.3.2 The quality factor, $Q_{\mathrm{s}}$, of the series circuit 302

12.3.3 The peak voltage across $R, L$ and $C \quad 305$

$\begin{array}{ll}\text { 12.3.4 } & \begin{array}{l}\text { Bandwidth and selectivity of a series } R L C \\ \text { circuit }\end{array}\end{array}$

12.4 Parallel resonance 308

12.4.1 Resonant frequency and frequency response of an ideal parallel circuit $\quad 308$

12.4.2 The quality factor, $Q_{\mathrm{p}}$, of an ideal parallel circuit 310

12.4.3 Bandwidth and selectivity of a parallel circuit 311

12.4.4 Resonance in a practical parallel circuit 311

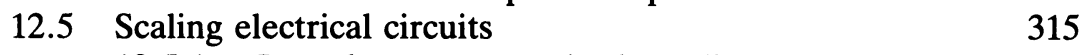

12.5.1 Impedance or magnitude scaling 315

12.5.2 Frequency scaling 316

12.5.3 Combined scaling 317

12.5.4 Universal resonant circuits 317

12.6 Passive and active filters 318

12.6.1 Passive band-pass filter 318

12.6.2 Passive band-stop filter 319

12.6.3 Active $R C$ filters $\quad 320$

$\begin{array}{lll}12.7 & \text { Selective resonance } & 320\end{array}$

12.8 Tuned coupled circuits 321

Unworked problems 323 
13 Harmonics and Fourier Analysis

13.1 Introduction 325

13.2 Harmonics 325

13.3 Trigonometric Fourier series 326

13.4 Waveform symmetry 332

13.5 Line spectra 335

13.6 Circuit response to a non-sinusoidal forcing function 338

13.7 r.m.s. value of a complex wave and the power supplied $\quad 340$

13.8 Effect of harmonics in a.c. systems 343

13.9 Harmonic analysis 343

Unworked problems $\quad 345$

14 Computer Solution of Electric Circuits 349

14.1 Introduction 349

14.2 Circuit description 351

14.3 Element description 351

14.4 Programming examples 357

15 Complex Numbers, Matrices, Determinants and Partial Fractions

15.1 Imaginary numbers 386

15.2 Complex numbers 387

15.3 Representation of complex numbers 387

15.4 Conjugate of a complex number 388

15.5 Sum and difference of complex numbers 388

15.6 Multiplication of complex numbers 389

15.7 Division of complex numbers 389

15.8 Powers and roots of complex numbers 390

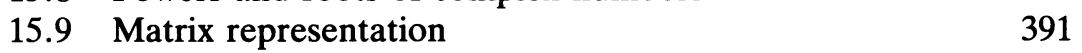

15.10 Matrix addition and subtraction 392

15.11 Matrix multiplication 392

15.12 The determinant of a square matrix 394

15.13 Minors and cofactors 395

15.14 Evaluating a determinant 395

15.15 The rule of Sarrus 396

15.16 Cramer's rule 396

15.17 Matrices and determinants containing complex
numbers

15.18 Partial fractions 397

Bibliography 401

Index $\quad 402$ 


\section{Preface}

Electrical Circuit Analysis and Design is intended for use with the early years of a first degree course in Electrical, Electronic and Control Engineering, and for Higher National Diploma and Certificate courses in Electrical and Electronic Engineering.

The main prerequisite to its use is a knowledge of the basic concepts of electricity, magnetism and mathematics; an introduction to calculus is more in the nature of a corequisite than a prerequisite.

The book has primarily been written for the student, and it is intended that readers should be able to teach themselves the analytical techniques involved. To this end, many fully worked examples are included in the body of the text, and a large number of unworked problems (with solutions) are included at the end of chapters. Throughout the book, both 'power' and 'electronic' circuit examples and problems have been included.

A 'plus' feature of the book is a chapter on the use of SPICE software (Simulated Program with Integrated Circuit Emphasis) for circuit analysis. Examples in this chapter range from resistive d.c. networks to a.c. solutions and transient analysis, and illustrate the practical advantages of this software, which is pre-eminent in the field of circuit analysis.

When writing the book, I decided that it should be written from a logical teaching viewpoint. That is, as with a conventional course, the more understandable parts of circuit theory are treated first, after which the less easy but, technically, more interesting topics are covered.

Chapter 1 covers d.c. circuits and introduces the concept of basic elements and laws, including Kirchhoff's laws together with simple circuit analysis, and described dependent and independent sources.

In chapter 2, we take a first look at network analysis using mesh, nodal and loop analysis. In undergraduate and some HND courses, the latter usually involves a knowledge of network topology, which is also introduced. Finally, an introduction to the duality between circuits having similar mesh and nodal equations is given. 
In order to understand circuit analysis fully, the reader should have a grasp of a number of circuit theorems and this, for d.c. circuits, is provided in chapter 3.

To move on to alternating current theory, the reader needs to understand the basis of circuits containing energy storage elements, this information being provided in chapter 4 . Here we deal with capacitors, inductors and mutual inductance. Engineers have devised the 'dot' notation to deal with the latter, and this is fully explained in this chapter.

In chapter 5, we look at some of the many interesting aspects of alternating current theory, including phasors and phasor diagrams, complex impedance and admittance, together with series and parallel combinations of elements and circuits. Also covered are power and power factor, together with complex power. Next, in chapter 6 , we apply a range of circuit theorems to a.c. networks.

Power-based electrical engineers have a particular interest in polyphase circuits, and this topic is comprehensively covered in chapter 7. This chapter describes and analyses many aspects of three-phase systems, including power measurement and symmetrical components.

Two-port networks are of great significance to electronics and telecommunications engineers and, in chapter 8 , the reader is introduced to $y$, $z, h$ and transmission parameters, together with the relationship between them.

In chapter 9 we meet the transformer, both 'ideal' and 'linear'. A knowledge of these is vital to both electrical and electronic engineers alike.

In chapter 10 , we deal comprehensively with the transient analysis of circuits. A practice in many courses is to deal with this topic using two or sometimes three different techniques, each time covering very similar ground! In this chapter we look, initially, at the process of solving first- and second-order circuits by classical methods. These methods generally have a number of disadvantages, which are overcome by the use of the Laplace transform method; the latter is used throughout the remainder of the chapter.

While the Laplace transform method has the minor drawback that we need to spend a little time looking at the development of Laplace transforms before moving on to circuit analysis, it has the great advantage that the solution of circuits (both without and with initial conditions) becomes relatively straightforward. This chapter covers step function (d.c.) and a.c. analysis of first- and second-order circuits, together with transients in magnetically coupled circuits.

A feature of many electrical and electronic courses is the treatment of the frequency response of circuits, and this is described in chapter.11. Additionally, an introduction to complex frequency and the $s$-plane is provided and, equally importantly, the transformation of time-domain 
impedance into its equivalent $s$-domain impedance is covered. Frequency response is described in terms of Bode diagrams, and the method of drawing the diagrams is outlined in a straigthforward manner for both firstand second-order circuits.

Resonance occurs both in electronic and power circuits, and comprehensive coverage of series and parallel resonance is provided in chapter 12. Additional features in this chapter include frequency scaling, selective resonance and tuned coupled circuits.

In chapter 13 the attention of the reader is directed to harmonics and Fourier analysis. A knowledge of Fourier analysis is vital for all engineers, and the chapter includes such topics as waveform symmetry, line spectra, circuit response and the effect of harmonics in a.c. systems. Also included is a section on harmonic analysis.

In chapter 14 we meet one of the most powerful software packages available for analysis of electrical and electronic circuits, namely SPICE (Simulated Program with Integrated Circuit Emphasis). This software, which is both fast and versatile, is widely available both in full and in educational versions, and can be used to solve almost any electrical problem. The solution of a wide range of problems is included in this chapter.

Chapter 15 is devoted to a number of mathematical 'tools' needed by engineers and technicians, namely complex numbers, matrices, determinants and partial fractions. 


\section{Acknowledgements}

I acknowledge with thanks the assistance I have received from Derek Hopewell of Nottingham Polytechnic, Mr F. W. Senior, M.Sc., former Senior Lecturer at the Staffordshire University and, in particular for his not inconsiderable assistance, Lionel Warnes of Loughborough University. I would also like to thank Mr A. Lewis, Director of the Open Terminal Computer Centre, Stevenage.

Finally, grateful thanks are due to my wife, without whose assistance and support the book would not have been possible. 